\title{
Duodenal carcinoma at the ligament of Treitz. A molecular and clinical perspective
}

\author{
Peter T Kalogerinis ${ }^{1 \dagger}$, John E Poulos ${ }^{2 \dagger}$, Andrew Morfesis ${ }^{3+}$, Anthony Daniels ${ }^{2 \dagger}$, Stavroula Georgakila ${ }^{4 \dagger}$, \\ Thomas Daignualt ${ }^{2}$, Alexandros G Georgakilas ${ }^{5^{*+}}$
}

\begin{abstract}
Background: There is very small occurrence of adenocarcinoma in the small bowel. We present a case of primary duodenal adenocarcinoma and discuss the findings of the case diagnostic modalities, current knowledge on the molecular biology behind small bowel neoplasms and treatment options.

Case: The patient had a history of iron deficiency anemia and occult bleeding with extensive workup consisting of upper endoscopy, colonoscopy, capsule endoscopy, upper gastrointestinal series with small bowel follow through and push enteroscopy. Due to persistent abdominal pain and iron deficiency anemia the patient underwent push enteroscopy which revealed adenocarcinoma of the duodenum. The patient underwent en-bloc duodenectomy which revealed T3N1M0 adenocarcinoma of the 4th portion of the duodenum.

Conclusions: Primary duodenal carcinoma, although rare should be considered in the differential diagnosis of occult gastrointestinal bleeding when evaluation of the lower and upper Gl tract is unremarkable. We discuss the current evaluation and management of this small bowel neoplasm.
\end{abstract}

\section{Background}

Malignancies of the small intestine are uncommon, accounting for only roughly $1-2 \%$ of malignant gastrointestinal (GI) diseases [1]. When compared to other cancer diagnosis rates, small bowel cancers average roughly 6000 per year in the United States [2]. As suggested by two recent major epidemiological studies on patients with small bowel neoplasms (SBN) identified from the National Cancer Data Base (NCDB, 19852005) and the Surveillance Epidemiology End Results (SEER, 1973-2004) database [3] as well as the Connecticut Tumor Registry [4], over the past twenty years, carcinoid tumors have become the most common SBN followed by adenocarcinomas (AC). A significant observation based on these studies is that from 1973 to 2004, the incidence of carcinoid tumors increased more than 4-fold ( 2.1 to 9.3 per million), with similar increases in the incidence of $\mathrm{AC}$, stromal tumors, and lymphomas [3]. While $\mathrm{AC}$ is the most common malignancy of the

\footnotetext{
* Correspondence: georgakilasa@ecu.edu

† Contributed equally

${ }^{5}$ Department of Biology, Thomas Harriot College of Arts and Sciences, East

Carolina University, Greenville, North Carolina 27858, USA

Full list of author information is available at the end of the article
}

duodenum the most common site of SBN is the ileum (Table 1), with a preponderance of lymphoma and carcinoids [5]. Among patients with Crohn's disease AC is most noted in ileum rather than the more proximal small bowel [6]. AC of the $3^{\text {rd }}$ and $4^{\text {th }}$ portions of the duodenum is very uncommon [7], and only $45 \%$ of duodenal carcinomas occur in that region [8].

The low incidence of SBN may be due to several theoretical factors including small bowel transit time, host immunologic factors, and/or epithelial toxin exposure [9-11]. Dietary factors that may increase the risk of small bowel AC may include diets high in red meat, or the consumption of smoked or salted foods [12]. There may be an increased risk of SBN with a diet rich in refined carbohydrates, and sugar [13]. Hereditary syndromes or conditions that can predispose to SBN include Muir-Torre syndrome [14], hereditary nonpolyposis colorectal cancer (HNPCC), familial adenomatous polyposis (FAP) and it's variants such as Gardner's Syndrome [15] Celiac Sprue, Puetz-Jeghers, Crohn's Disease [16] and Juvenile Polyposis Syndrome [17].

Primary SBNs are much rarer than those that arise from a secondary neoplastic process [16]. Metastasis from the stomach, ovary, colon and uterus can involve 
Table 1 Accumulating reports on the incidence of small bowell malignancies: type, location and survival rates

\begin{tabular}{|c|c|c|c|c|}
\hline \multicolumn{5}{|c|}{ Incidence (\%) of small bowel malignancy based on histology } \\
\hline Adenocarcinoma & $\begin{array}{l}\text { Carcinoid } \\
\text { Tumors }\end{array}$ & Lymphoma & Sarcoma & Reference \\
\hline 40 & 25 & 25 & 10 & [69] \\
\hline 47 & 28 & 12 & 13 & [70] \\
\hline 40 & 20 & 27 & 9 & [71] \\
\hline 36.9 & 37.4 & 17.3 & 8.4 & {$[4]$} \\
\hline 27 & 33 & 16.3 & 7.1 & [3] \\
\hline \multicolumn{5}{|c|}{ Incidence (\%) of small bowel adenocarcinoma based on location } \\
\hline & Duodenum & Jejunum & lleum & Reference \\
\hline & 72 & 37 & 21.4 & [69] \\
\hline & 47 & 29 & 24 & [70] \\
\hline & 41 & 34 & 25 & [71] \\
\hline & 56 & 15.6 & 13 & [4] \\
\hline & 53 & 19.7 & 12.9 & [3] \\
\hline \multicolumn{5}{|c|}{ Incidence (\%) of small bowel tumors by location } \\
\hline & Duodenum & Jejunum & lleum & Reference \\
\hline & 24.6 & 36.9 & 38.3 & [69] \\
\hline & 32 & 36 & 32 & [70] \\
\hline & 23 & 33.3 & 41.6 & [71] \\
\hline & 33 & 12 & 26 & [4] \\
\hline & 25 & 15.3 & 29.7 & [3] \\
\hline \multicolumn{5}{|c|}{ Five year survival rate (\%) of small intestine adenocarcinoma based on disease stage [2] } \\
\hline Stage I & 55 & & & \\
\hline Stage $\| \mathrm{A}$ & 49 & & & \\
\hline Stage \| B & 35 & & & \\
\hline Stage III A & 31 & & & \\
\hline Stage III B & 18 & & & \\
\hline Stage IV & 5 & & & \\
\hline
\end{tabular}

the small bowel by direct means or via peritoneal involvement [18]. Metastatic tumors from breast, melanoma and lung appear to spread to the duodenum by blood and lymphatic pathways.

The mean age of presentation of $\mathrm{SBN}$ is 64 with a range of 47-87 years [3,19]. Obscure GI bleeding (OGIB) is the most common symptom as $50 \%$ of those with SBN present with OGIB, however it should be noted that only $4 \%$ of OGIB cases are caused by SBN [20]. Due to the vague presentation a delayed diagnosis or misdiagnosis is common [9], with an average delay of six to eight months between the time of symptom onset and diagnosis [21].

\section{Investigations}

SBN are usually discovered during the evaluation of OGIB, anemia, and abdominal pain. Abdominal X-ray may help in showing obstruction, however duodenal carcinomas especially those in the $3^{\text {rd }}$ and $4^{\text {th }}$ portions of the organ are often missed on barium $\mathrm{x}$-ray examination [22] yielding a definite diagnosis in less than $5 \%$ of cases
[23]. Colonoscopy with ileoscopy may be useful in detecting lesions in the terminal ileum and excluding a colonic source of pathology. Both sporadic duodenal adenomas and those associated with hereditary cancer syndromes have a higher risk of colorectal cancer (CRC) and these patients should be evaluated with colonoscopy [24]. Likewise those with CRC associated with hereditary cancer syndromes should be evaluated for SBN [17].

The utilization of CT enterocolysis (CTE) in the detection of SBN overcomes the individual short comings of both barium enterocolysis and conventional CT and utilizes the advantages of both into a single technique and has begun to substitute enterocolysis in clinical practice [25]. Contrast-enhanced and water-enhanced multidetector CTE has a sensitivity of $84.7-95 \%$ and $96-$ $100 \%$ specificity for the detection of SBN [26,27].

Tocchi et al. found that upper GI endoscopy had a $36 \%$ false-negative result rate in identifying duodenal tumors due to depth of insertion. Push enteroscopy (PE) provides many benefits including direct visualization of 
lesions in the proximal duodenum and jejunum, allowing the ability to biopsy and provide therapeutic measures in cases of bleeding. The investigation of obscure bleeding by PE may find a diagnostic cause in $25-28 \%$ of cases $[28,29]$. PE and Sonde enteroscopy have shown a diagnostic yield of $6 \%$ for SBN in patients undergoing the procedure for evaluation of OGIB [30]. However PE as well as CT and small bowel barium studies may fail to detect $50 \%$ of small bowel lesions [31].

Capsule endoscopy (CE) has been shown to be a safe and effective non invasive method of diagnosis for small bowel abnormalities [32,33] and allows a more detailed inspection of the small intestine. CE has also been shown to detect duodenal adenomatous polyps in $64.3 \%$ of those who also have FAP [34]. An absolute contraindication to CE is GI obstruction. Relative contraindications to CE include pregnancy, GI motility disorders, or large diverticuli within the small bowel [35]. CE may detect more SBN than CTE in patients with OGIB having an overall accuracy of $84.7 \%[36]$.

It has been shown that CE diagnosed SBN in 9\% of patients who underwent the procedure for investigation of OGIB and in $8.3 \%$ of those who were investigated for non bleeding causes [37]. However in a pooled metaanalysis it was found that $\mathrm{CE}$ had a $20 \%$ miss rate for SBN [38]. Similar to our case where CE failed to reveal $\mathrm{AC}$ of the duodenum, there are increasing reports in the literature of failure of CE to detect solitary SBN [39,40]. It has also been shown that after an initial negative $C E$ study a repeat CE may reveal significant lesions in $20 \%$ of cases [41]. Etiologies for failure to detect lesions by $\mathrm{CE}$ may be due to rapid capsule passage through the proximal small bowel, decreased visibility due to luminal contents, or failure to reach the colon. Thus, based on certain clinical scenarios a negative finding on CE may not exclude significant small bowel pathology and further investigation may be warranted.

Balloon assisted enteroscopy (BAE) utilizing either single balloon enteroscopy (SBE) or double balloon enteroscopy (DBE) offers a number of advantages when compared to other small bowel imaging studies. The advantages include visualization of the entire small bowel with the ability to provide tissue diagnosis and provide therapeutic modalities such as control of bleeding and dilation of strictures $[42,43]$. Optimal visualization of the small bowel may involve both oral and anal insertion. Initial studies indicated a greater diagnostic yield and higher rate of endoscopic intervention for DBE vs. SBE[44]. However a recent study comparing SBE vs DBE revealed identical procedure times, depth of insertion, and a slight increase in identification and treatment of lesions with SBE vs DBE[45]. Studies have calculated that BAE and $\mathrm{CE}$ are in agreement $61-74 \%$ of the time and $96 \%$ of the time when diagnosing large tumors [46]. In regards to SBN, BAE can often find lesions originally missed by $\mathrm{CE}$ and is suggested as a follow up study to a negative CE exam [47]. Arakawa reported equal diagnostic yields for both $\mathrm{CE}$ and $\mathrm{BAE}$ with false negative cases of $\mathrm{CE}$ and $\mathrm{BAE}$ due to failure to detect lesions in the proximal small bowel and inaccessibility of the site, respectively. In a recent meta-analysis comparing $\mathrm{CE}$ and $\mathrm{BAE}$, there was no significant difference in yields between the two modalities $61 \%$ vs. $56 \%$, respectively[48]. Sub analysis of data did reveal a slight advantage in favor of $\mathrm{CE}$ and this appeared to be to the utilization of a single insertion approach by BAE. When BAE was performed using a dual insertion approach via the oral and anal route the yield was $74 \%$ vs. $54 \%$ for CE [48].

The failure of BAE to show superiority over CE in the detection of lesions may be due to complete evaluation of the entire small bowel in only $60-70 \%$ of cases $[43,49]$. A disadvantage of the procedure is the time needed to visualize the small bowel [50], its invasiveness, and the reports of intestinal necrosis [51], perforation and acute pancreatitis [52] post procedure. Due to the failure of a true gold standard in evaluation of the small bowel utilization of both these procedures may be complementary.

\section{Treatment and Prognosis}

Duodenal AC has a shorter median overall survival rate compared with patients with tumors located in the jejunum or ileum [53]. SBNs are more common in men [54] and are higher in African Americans than those of Caucasian decent. It has been reported that SBN in African American men has increased in prevalence by $120 \%$ over the last 3 decades [55]. In regards to 5 year survival, earlier stages have a better prognosis [56]. Around $58 \%$ of patients with small intestine AC present at late stages (III and IV), in contrast with $28 \%$ of patients with CRC[55] (Table 1). The overall median survival of patients with duodenal AC has been reported as 18 months and the 5-year survival as $23 \%$ [57].

Historically treatment of SBN has relied solely upon surgery as the only curative treatment and has been divided between two techniques which are pancreatoduodenectomy (PD) and duodenal segmentectomy (DS). PD is considered to be the procedure of choice. DS, is used for more palliative measures [8]. Studies have shown that DS is a better option for distal duodenal tumors without advanced disease, in which case PD is considered a better option $[8,57,58]$. Surgical intervention has shown to provide a curative resection in $40-65 \%$ of patients. The five year survival rate for nonresected tumors being is $15-30 \%$ compared to $40-60 \%$ survival rate for those who had resection [53]. A large tumor or positive lymph node metastasis does not 
invalidate resection as long as a negative margin can be attained, and in terms of clearance of regional lymph nodes the difference between both procedures is negligible [57].

Chemotherapy is mainly utilized as a palliative measure and has not been well studied due to the low prevalence of $\mathrm{AC}$ in the small bowel. The largest published study investigating chemotherapeutic measures for small bowel AC involved 14 subjects with metastatic small bowel $\mathrm{AC}$ and involved a chemotherapeutic regiment containing 5-fluorouracil (5-FU) [59]. Patients had a median survival of 9 months. A more recent investigation reported advanced small bowel AC treated with infusional 5-FU-based regimens had a response rate of $37.5 \%$ and a median survival of 13 months [60]. A case report using onastat, tegafur, and gimestat (otherwise known as S-1chemotherapy) showed remission of primary AC of the duodenum [61]. Newer agents found to be effective for CRC also may have an effect on small bowel AC.

\section{Genetic and Molecular Biology Considerations}

Due to the rarity of SBN, little has been published about oncogenesis as well as clinicopathologic features [62]. An analysis of SBN found that $53 \%$ had point mutations in the Ki-ras gene [63] similar to mutations found in CRC[64], and that overall frequencies of Ki-ras and p53 gene mutations are similar in both [63].

In terms of the APC gene, SBN have a lower rate of mutations involving the APC gene compared to its involvement in CRC [63]. Duodenal carcinoma is the second most common carcinoma in FAP and the low rate of APC mutations in duodenal adenocarcinoma refer primarily to sporadic adenocarcinomas and not those associated with FAP and its variants. Thus these recent findings suggest that the APC gene is not involved with SBN in man $[63,65]$. An extensive study revealed all duodenal AC tumors to be positive for mismatch repair (MMR) on genes hMHL1 and hMSH2 but no mutations were found in the mutation cluster region (MCR) of the APC gene [66]. Thus suggesting that molecular mechanism leading to the development of AC of the small intestine may be different than those leading to CRC. Cytogenetical studies on primary duodenal AC revealed several abnormalities that resulted in partial or complete losses or gains chromosomally [67]. The detection of biallelic MMR gene mutations in pediatric duodenal cancer further supports the idea of MMR deficiencies as a duodenal cancer predisposition syndrome [68].

\section{Case Presentation}

A 66 year old African-American female presented with complaints of 10 pound weight loss and a four week history of intermittent abdominal pain, nausea, and non bloody emesis. Her medical history was significant for type 2 diabetes mellitus, hypertension, coronary heart disease, and peptic ulcer disease. The patient denied any significant alcohol or tobacco use. Her family history was positive for colon cancer. Physical exam and laboratory tests were unremarkable. A colonoscopy and an esophagogastroduodenosopy (EGD) to the second portion of the duodenum were performed revealing three small tubular adenomas of the colon and helicobacter pylori gastritis. She was treated with two weeks of amoxicillin 1 gram and clarithromycin $500 \mathrm{mg}$ orally twice daily for two weeks.

She did well after the antibiotic therapy and was not seen again until two years later when she was hospitalized for severe, symptomatic anemia. For eight months prior to admission, she noted recurrent intermittent abdominal pain and nausea with non-bloody emesis and progressive fatigue. She denied melena or hematochezia. On admission, her hemoglobin was $5.4 \mathrm{gm} / \mathrm{dl}$ and hematocrit was $17.3 \%$, with a normal MCV. Her stool was hemoccult positive. She required a transfusion of four units of packed red blood cells. An EGD to the second portion of the duodenum revealed mild gastritis, negative for $H$. pylori. A CT scan of the abdomen and pelvis with oral contrast was unremarkable. An outpatient wireless capsule endoscopy was ordered; however, it was cancelled due to the reluctances of the patient to swallow the capsule.

Patient again required hospitalization for severe symptomatic anemia with hemoglobin of $5 \mathrm{gm} / \mathrm{dl}$. Her indices and iron studies at this time were consistent with iron deficiency anemia. She denied melena, hematochezia or bloody emesis. She required another 4 unit blood transfusion. An EGD was performed and again it was unremarkable. Due to her inability to swallow the wireless capsule, the endoscope was used to deliver the capsule into the stomach. The study however was limited due to retained debris in the mid duodenum, significantly limiting visualization of the small bowel.

Patient presented three months later with symptomatic anemia, hemoglobin of $4.6 \mathrm{gm} / \mathrm{dl}$ and hematocrit of $14.2 \%$. She required four units of packed red blood cells. Two days prior to admission, she noted black tarry stools. Physical exam was unremarkable with the exception of palpable tenderness in the epigastric and left upper quadrant.

Three way abdominal $x$-ray of the abdomen was performed and was unremarkable. MRA with and without contrast and CT scan of abdomen and pelvis with oral contrast showed no evidence of localized abnormality in the abdomen or pelvis in terms of solid organs or vasculature. An upper GI series with KUB was performed revealing eccentric broadband defect along the inner or 


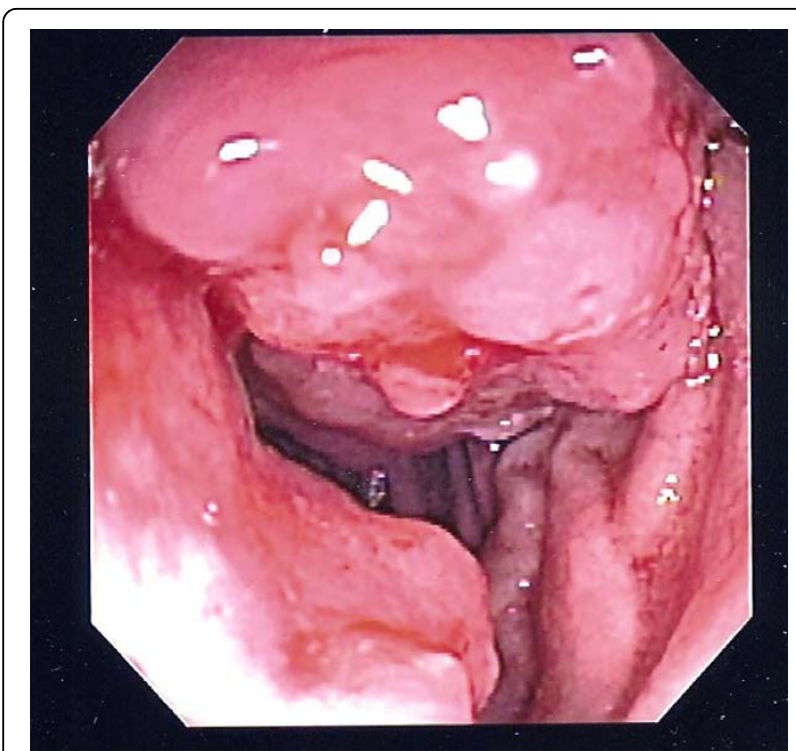

Figure 1 Endoscopic image of the small bowel neoplasm. The endoscopic image of the cancerous mass showing it's large irregular pattern and causing narrowing of the duodenum.

medial wall of the 2nd portion of the duodenum, with the other portions being unremarkable.

Push enteroscopy was performed which revealed a circumferential fungating mass in the 4th portion of the duodenum, which was actively oozing blood and upon further investigation it appeared the mass extended to the ligament of Treitz (Figure 1). The area was biopsied and tattooed. Pathology from biopsy revealed moderately differentiated AC with lymphovascular invasion. Patient underwent exploratory laparotomy and the small bowel was examined with the tumor being present at the ligament of Treitz. The tumor was resected en bloc and two lymph nodes were collected. The small bowel was reconnected using a primary Gambee anastamosis.

Pathology from surgical specimen revealed T3N1M0 $\mathrm{AC}$, with the tumor being 4.5 centimeters in greatest dimension and showing invasion through the muscularis propria and into the sub-serosa but not through it. The resected margins were clear. Of the two lymph nodes collected one was positive for metastatic carcinoma, with the tumor nodule measuring 1.5 centimeters in diameter and showing invasion through the lymphatic capsule.

Patient was referred to oncology for consultation however did not follow up as scheduled, and has been lost to follow up care.

\section{Conclusions}

In patients presenting with OGIB, iron deficiency anemia or other warning signs and symptoms SBN, should be considered in the differential due to its insidious presentation. In terms of oncogenesis more research is needed in order to better understand its development, but evidence suggests a multi-factorial genetic cause. Options in the evaluation of small bowel pathology may require $\mathrm{CE}, \mathrm{BAE}$, and/or $\mathrm{CTE}$. An initial approach may be with CE or CTE due to the fact it is non invasive with subsequent utilization of BAE if the evaluation is unrevealing or if lesions are detected that require tissue confirmation. Surgery is the best curative option in terms of treatment of these types of malignancies with PD being better for advanced diseases and DS for disease of the distal duodenum. Chemotherapeutic options are improving and providing longer survival rates and palliative benefits.

\section{Consent}

Written informed consent was obtained from the patient for publication of this case report and any accompanying images. A copy of the written consent is available for review by the Editor-in-Chief of this journal.

\section{Abbreviations}

Gl: Gastrointestinal; SBN: Small bowel neoplasms; NCDB: National Cancer Data Base; SEER: Surveillance Epidemiology End Results; AC:

Adenocarcinoma; HNPCC: hereditary nonpolyposis colorectal cancer; FAP: familial adenomatous polyposis; OGIB: Obscure Gl bleeding; CRC: Colorectal cancer; CTE: CT enterocolysis; PE: Push enteroscopy; CE: Capsule endoscopy; BAE: Balloon assisted enteroscopy; SBE: Single Balloon enteroscopy; DBE: Double Balloon enteroscopy; PD: pancreatoduodenectomy; DS: duodenal segmentectomy; 5-FU: 5-fluorouracil; MMR: Mismatch repair; MCR: mutation cluster region; EGD: esophagogastroduodenosopy

\section{Acknowledgements}

This work was partially supported by funds provided to Dr. Georgakilas by a 2009/2010 ECU Research/Creative Activity Award.

\section{Author details}

${ }^{1}$ Methodist University Physician Assistant Program, Fayetteville, North Carolina, USA. ${ }^{2}$ Fayetteville Gastroenterology Associates, Fayetteville, North Carolina, USA. ${ }^{3}$ Owen Drive Surgical Clinic of Fayetteville, Fayetteville, North Carolina, USA. ${ }^{4}$ Harris Birthright Research Centre for Fetal Medicine, Department of Obstetrics and Gynecology, Kings College University Hospital, London SE5 9SR, UK. ${ }^{5}$ Department of Biology, Thomas Harriot College of Arts and Sciences, East Carolina University, Greenville, North Carolina 27858, USA.

\section{Authors' contributions}

FAM, JEP, TD, and AD contributed directly and equally to patient care; PTK, $\mathrm{SG}, \mathrm{AGG}$, and JEP contributed to literature research and analysis of the data; All authors contributed in the writing and critical development of the manuscript. All authors have read and approved the final manuscript.

\section{Competing interests}

The authors declare that they have no competing interests.

Received: 27 April 2010 Accepted: 17 September 2010 Published: 17 September 2010

\section{References}

1. Moglia A, Menciassi A, Dario P, Cushieri A: Clinical update: endoscopy for small-bowel tumours. Lancet 2007, 370(9582):114-116.

2. Cancer Facts \& Figures 2009. Atlanta: American Cancer Society 2009.

3. Hatzaras I, Palest JA, Abir F, Sullivan P, Kozol R, Dudrick S, Longo W: Smallbowel tumors: epidemiological and clinical characteristics of 1260 cases from the connecticut tumor registry. Arch Surg 2007, 142(3):229-235. 
4. Bilimoria K, Bentrem D, Wayne J, Ko C, Bennet C: Small bowel cancer in the United States: changes in epidemiology, treatement, and survival over the last 20 years. Ann Surg 2009, 249(1):63-71.

5. Neugut Al, Jacobson JS, Suh S, Mukherjee R, Arber N: The epidemiology of cancer of the small bowel. Cancer Epidem Biomar 1998, 7(3):243-251.

6. Lashner B: Risk factors for small bowel cancer in Crohn's diesease. Dig Dis Sci 1992, 37(8):1179-1184

7. Markogiannakis H, Theodorou D, Toutouzas K, Gloustianou G, Katsaragakis K, Bramis I: Adenocarcinoma of the third and fourth portion of the duodenum: a case report and review of the literature. Cases J 2008, 1(1):98.

8. Tocchi A, Mazzoni G, Puma F, Miccini M, Cassini D, Bettelli E, Tagliacozzo S Adenocarcinoma of the Third and Fourth Portions of the Duodenum Results of Surgical Treatment. Arch Surg 2003, 138(1):698-702.

9. DiSario JA, Burt RW, Vargas H, McWhorter WP: Small bowel cancer: epidemiological and clinical characteristics from a population based registry. Am J Gastroenterol 1994, 89(5):699-701.

10. Ciresi $\mathrm{DL}$, Scholten DJ: The continuing clinical dilemma of primary tumors of the small intestine. Am Surg 1995, 61(8):698-702.

11. Intner T, Whang E, Ashley S: Small Intestine. In Essentials of Surgery. Edited by: Stucchi JBA. Philadelphia: Saunders; 2006:286-295.

12. Chow WH, Linet MS, McLaughlin LK, Hsing AW, Chien HT, Blot WJ: Risk factors for small intestine cancer. Cancer Cause Control 1993, 4:163-169.

13. Negri E, Bosetti C, La Vecchia C, Fioretti F, Conti E, Franceschi S: Risk factors for adenocarcinoma of the small intestine. Int J Cancer 1999, 82:171-4.

14. Rubinstein W, Weissman S: Managing hereditary gastrointestinal cancer syndromes: the partnership between genetic counselors and gastroenterologists. Nat Clin Pract Gastr 2008, 5:10.

15. Overman M: Recent advances in the management of adenocarcinoma of the small intestine. Gastrointest Cancer Res 2009, 3:90-96.

16. Gill S, Heuman D, Mihas A: Small intestinal neoplasms. J Clin Gastroenterol 2001, 33(4):267-282.

17. Burt R: Genetics and Inherited Syndromes of Colorectal Cancer. Gastroenterol Hepatol 2009, 5(2):119-130.

18. Berger A, Cellier C, Daniel C, Kron C, Riquet M, Baribier J, Cugnenc P, Landi B: Small bowel metastasis from primary carcinoma of the lung: clinical findings and outcome. Am J Gastroenterol 1999, 94:1884-1887.

19. Scott-Coombes DM, Williamson RCN: Surgical Treatment of Primary Duodenal Carcinoma: A Personal Series. Brit J of Surg 1994, 81:1472-1474.

20. Yamagami H, Oshitani N, Hosomi S, SueKane T, Kamata N: Usefulness of Double-balloon endoscopy in the diagnosis of malignant small-bowel tumors. Clin Gastroenterol Hepatol 2008, 6(11):1202-1205.

21. Wilson JM, Melvin DB, Gray GF, Thorbjarnarson B: Primary malignancies of the small bowel: a report of 96 cases and review of the literature. Ann Surg 1974, 180:175-179.

22. Thompson N: Duodenal tumors. In Current medical diagnosis and treatment: surgery. Edited by: Doherty G. New York: McGraw-Hill; 2010:

23. Zuckerman G, Prakash C, Askin M, Lewis B: AGA technical review on the evaluation and management of occult and obscure gastrointestinal bleeding. Gastroenterology 2000, 118:201-221.

24. Murray MA, Zimmerman MJ, Ee HC: Sporadic duodenal adenoma is associated with colorectal neoplasia. Gut 2004, 53(2):261-265.

25. Raptopoulos V, Schwartz RK, McNicholas MM, Movson J, Pearlman J, Joffe N: Multiplanar helical CT enterography in patients with Crohn's Disease. AJR Am J Roentgenol 1997, 169(6):1545-1550.

26. Boudiaf M, Jaff A, Soyer P, Bouhnik $Y$, Hamzi L, Rymer R: Small-bowel diseases: prospective evaluation of multi-detector row helical ct enteroclysis in 107 consecutive patients. Radiology 2004, 233(2):338-344

27. Pilleul F, Penigaud M, Milot L, Saurin JC, Chayvialle JA, Valette PJ: Possible Small-bowel neoplasms: contrast-enhanced and water-enhanced multidetector ct enteroclysis. Radiology 2006, 241(3):796-801.

28. Ell C, Remke S, May A, Helou L, Henrich R, Mayer G: The first prospective controlled trial comparing wireless capsule endoscopy with push enteroscopy in chronic gastrointestinal bleeding. Endoscopy 2002, 34(9):685-689.

29. Ge ZZ, Hu YB, Xiao SD: Capsule endoscopy and push enteroscopy in the diagnosis of obscure gastrointestinal bleeding. Chin Med J 2004 117(7):1045-1049.

30. Berner JS, Mauer K, Lewis BS: Push and sonde enteroscopy for the diagnosis of obscure gastrointestinal bleeding. Am J Gastroenterol 1994, 89(12):2139-2142.
31. Kariv $\mathrm{R}$, Arber N: Malignant tumors of the small intestine - new insights into a rare disease. Isr Med Assoc J 2003, 5(3):188-192.

32. Appleyard M, Fireman Z, Glukhovsky A, Jacob H, Shreiver $R$ Kadirkamanathan S, Lavy A, Lewkowicz S, Scapa E, Shofti R, et al: A randomized trial comparing wireless capsule endoscopy with push enteroscopy for the detection of small-bowel lesions. Gastroenterology 2000, 119(6):1431-1438

33. Napierkowski JJ, Maydonovitch CL, Belle LS, Brand WT Jr, Holtzmuller KC Wireless capsule endoscopy in a community gastroenterology practice. Clin Gastroenterol 2005, 39(1):36-41.

34. Katsinelos P, Kountouras J, Chatzimavroudis G, Zavos C, Pilpilidis I, Fasoulas K, Paroutoglou G: Wireless capsule endoscopy in detecting small-intestinal polyps in familial adenomatous polyposis. World $J$ Gastroenterol 2009, 15(48):6075-6079.

35. Beard C, Poulos JE, Kalle J, Kumar A, V K: Capsule endoscopy: what role for this new technology? JAAPA 2007, 20(9):32-38

36. Voderholzer WA, Ortner M, Rogalla P, Beinhölzl J, Lochs H: Diagnostic yield of wireless capsule enteroscopy in comparison with computed tomography enteroclysis. Endoscopy 2003, 35(12):1009-1014.

37. Cobrin GM, Pittman RH, Lewis BS: Increased diagnostic yield of small bowel tumors with capsule endoscopy. Cancer 2006, 107(1):22-27.

38. Lewis BS, Eisen GM, Friedman S: A Pooled analysis to evaluate results of capsule endoscopy trials. Endoscopy 2005, 37(10):960-965.

39. Postgate A, Despott E, Burling D, Gupta A, Phillips R, O'Beirne J, Patch D, Fraser C: Significant small-bowel lesions detected by alternative diagnostic modalities after negative capsule endoscopy. Gastrointest Endosc 2008, 68(6):1209-1214

40. Chong AK, Chin BW, Meredith CG: A Pooled analysis to evaluate results of capsule endoscopy trials. Gastrointest Endosc 2006, 64(3):445-449.

41. Bar-Meir S, Eliakim R, Nadler M, Barkay O, Fireman Z, Scapa E, Chowers Y, Bardan E: Second capsule endoscopy for patients with severe iron deficiency anemia. Gastrointest Endosc 2004, 60(5):711-713.

42. Ross W: Small bowel imaging: multiple paths to the last frontier. Gastrointest Endosc 2008, 68(6):1117-1121.

43. Arakawa D, Ohmiya N, Nakamura M, Honda W, Shirai O, Itoh A, Hirooka Y, Niwa $Y$, Maeda O, Ando T, et al: Outcome after enteroscopy for patients with obscure gi bleeding:diagnostic comparison between doubleballoon endoscopy and videocapsule endoscopy. Gastrointest Endosc 2009, 69(4):866-874

44. May A: Balloon Enteroscopy: Single-and Double-Balloon Enteroscopy. Gastrointest Endosc Clin N Am 2009, 19(3):349-356.

45. Efthymiou M, Desmond P, Taylor AC: Single Balloon Enteroscopy Versus Double Balloon Enteroscopy, Preliminary Results of a Randomized Controlled Trial. Gastrointest Endosc 2010, 71(5):AB122-123.

46. Mehdizadeh S, Ross A, Gerson L, Leighton J, Chen A, Schembre D, Chen G, Semrad C, Kamal A, Harrison EM, et al: What is the learning curve associated with double-balloon enteroscopy? Technical details and early experience in 6 u.s. tertiary care centers. Gastrointest Endosc 2006, 64(5):740-750

47. Ross A, Mehdizadeh S, Tokar J, Leighton JA, Kamal A, Chen A, Schembre D, Chen G, Binmoeller K, Kozarek R, et al: Double balloon enteroscopy detects small bowel mass lesions missed by capsule endoscopy. Dig Dis Sci 2008, 53(8):2140-2143

48. Chen X, Ran ZH, Tong JL: A Meta-analysis of the yield of capsule endoscopy compared to double-balloon enteroscopy in patients with small bowel diseases. World J Gastroenterol 2007, 13(32):4372-4378.

49. Gross SA, Stark ME: Initial experience with double-balloon enteroscopy at a U.S. center. Gastrointest Endosc 2008, 67(6):890-897.

50. Lo SK, Mehdizadeh S: Therapeutic uses of double-balloon enteroscopy. Gastrointest Endosc Clin N Am 2006, 16(2):363-376.

51. Yen HH, Chen YY, Su WW, Soon MS, Lin YM: Intestinal necrosis as a complication of epinephrine injection therapy during double-balloon enteroscopy. Endoscopy 2006, 38(5):542.

52. Honda K, Mizutani T, Nakamura K, Higuchi N, Kanayama K, Sumida Y, Yoshinaga S, Itaba S, Akiho $\mathrm{H}$, Kawabe K, et al: Acute pancreatitis associated with peroral double-balloon enteroscopy: a case report. World J Gastroenterol 2006, 12(11):1802-1804.

53. Dabaja BS, Suki D, Pro B, Bonnen M, Ajani J: Adenocarcinoma of the Small Bowel Presentation, Prognostic Factors, and Outcome of 217 Patients. Cancer 2004, 101(3):518-526. 
54. Horner MJ, Ries L, Krapcho M, Neyman N, Aminou R: Seer cancer statistics review, 1975-2006. Edited by: Health Nlo. Bethesda: Government Printing Office; 2009:

55. Haselkorn T, Whittemore AS, Lilienfeld DE: Incidence of small bowel cancer in the United States and worldwide: geographic, temporal, and racial differences. Cancer Cause Control 2005, 16(7):781-787.

56. Detailed guide: small intestine cancer. Edited by: Society AC. American Cancer Society; 2009:2009.

57. Kaklamanos IG, Bathe OF, Franceschi D, Camarda C, Levi J, Livingstone AS: Extent of resection in the management of duodenal adenocarcinoma. Am J Surg 2000, 179(1):37-41.

58. Han SL, Cheng J, Zhou HZ, Zeng QQ, Lan SH: The Surgical treatment and outcome for primary duodenal adenocarcinoma. J Gastrointest Cancer 2009, 40(1-2):33-37.

59. Jigyasu D, Bedikian AY, Stroehlein JR: Chemotherapy for primary adenocarcinoma of the small bowel. Cancer 1984, 53(1):23-25.

60. Crawley C, Ross P, Norman A, Hill A, Cunningham D: The Royal marsden experience of a small bowel adenocarcinoma treated with protracted venous infusion 5-fluorouracil. Br J Cancer 1998, 78(4):508-510.

61. Katakura $Y$, Suzuki M, Kobayashi M, Nakahara K, Matsumoto N, Itoh F: Remission of primary duodenal adenocarcinoma with liver metastases with s-1 chemotherapy. Dig Dis Sci 2007, 52(4):1121-1124.

62. Neugut Al, Marvin MR, Rella VA, Chabot JA: An overview of adenocarcinoma of the small intestine. Oncology 1997, 11(4):529-536.

63. Arai M, Shimizu S, Imai Y, Nakatsuru Y, Oda H, Oohara T, Ishikawa T: Mutations of the Ki-ras, p53, and APC genes in Adenocarcinomas of the Human Small Intestine. Int J Cancer 1997, 70(4):390-395.

64. Bos J: Ras Oncogenes in Human Cancer: A Review. Cancer Res 1989, 49(17):4682-4689.

65. Saurin JC, Gutknecht C, Napoleon B, Chavaillon A, Ecochard R, Scoazec JY, Ponchon T, Chayvialle JA: Surveillance of Duodenal Adenomas in Familial Adenomatous Polyposis Reveals High Cumulative Risk of Advanced Disease. J Clin Oncol 2004, 22(3):493-498.

66. Wheeler JM, Warren BF, Mortensen NJ, Kim HC, Biddolph SC, Elia G, Beck NE, Williams GT, Shepherd NA, Bateman AC, et al: An Insight into the genetic pathway of adenocarcinoma of the small intestine. Gut 2002, 50(2):218-223.

67. Gorunova L, Johansson B, Dawiskiba S, Andrén-Sandberg A, Mandahl N, Heim S, Mitelman F: Cytogenetically detected clonal heterogeneity in a duodenal adenocarcinoma. Cancer Genet Cytogenet 1995, 82(2):146-150.

68. Roy S, Raskin L, Raymond VM, Thibodeau SN, Mody RJ, Gruber SB: Pediatric duodenal cancer and biallelic mismatch repair gene mutations. Pediatr Blood Cancer 2009, 53(1):116-120.

69. Cunningham J, Aleali R, Aleali M, Brower S, Aufses J: Malignant Small Bowel Neoplasms Histopathologic Determinants of Recurrence and Survival. Ann Surg 1997, 225:300-306.

70. North JHPM: Malignant tumors of the small intestine: a review of 144 cases. Am Surg 2000, 66(1):46-51.

71. Howdle PDJP, Holmes GK, Houlston RS: Primary small bowel malignancy in the UK and its association with coeliac disease. QJM 2003, 96(5):345-353.

\section{Pre-publication history}

The pre-publication history for this paper can be accessed here: http://www.biomedcentral.com/1471-230X/10/109/prepub

doi:10.1186/1471-230X-10-109

Cite this article as: Kalogerinis et al:: Duodenal carcinoma at the ligament of Treitz. A molecular and clinical perspective. BMC Gastroenterology 2010 10:109.

\section{Submit your next manuscript to BioMed Central and take full advantage of:}

- Convenient online submission

- Thorough peer review

- No space constraints or color figure charges

- Immediate publication on acceptance

- Inclusion in PubMed, CAS, Scopus and Google Scholar

- Research which is freely available for redistribution

Submit your manuscript at www.biomedcentral com/submit
Biomed Central 